\title{
Economic Strain Deteriorates While Education Fails to Protect Black Older Adults Against Depressive Symptoms, Pain, Self-rated Health, Chronic Disease, and Sick Days
}

\author{
Shervin Assari ${ }^{*}$, Sharon Cobb ${ }^{2}$, Mohammed Saqib ${ }^{3}$, Mohsen Bazargan ${ }^{1,4}$ \\ 'Departments of Family Medicine, Charles R Drew University of Medicine and Science \\ ${ }^{2}$ School of Nursing, Charles R Drew University of Medicine and Science, Los Angeles, CA, United States \\ ${ }^{3}$ University of Michigan School of Public Health, Ann Arbor, MI, United States \\ ${ }^{4}$ Departments of Family Medicine, University of California, Los Angeles (UCLA), Los Angeles, CA, United States
}

Article Info

\section{Article Notes}

Received:June 1, 2020

Accepted: June 18, 2020

\section{${ }^{*}$ Correspondence:}

Shervin Assari, Departments of Family Medicine, College of Medicine, Charles R Drew University of Medicine and Science, 118th St, Los Angeles, CA, 90059, United States; Telephone No: 734-363-2678; Email: assari@umich.edu.

(C) 2020 Assari S. This article is distributed under the terms of the Creative Commons Attribution 4.0 International License.

\section{Keywords:}

Older adults

Socioeconomic position

Socioeconomic status

Education attainment

Financial difficulty

Economic strain

\section{Abstract}

Background: A large body of empirical evidence on Minorities' Diminished Returns (MDRs) suggests that educational attainment shows smaller health effects for Blacks compared to Whites. At the same time, economic strain may operate as a risk factor for a wide range of undesired mental and physical health outcomes in Black communities.

Aim: The current study investigated the combined effects of education and economic strain on the following five health outcomes in Black older adults in underserved areas of South Los Angeles: depressive symptoms, number of chronic diseases, pain intensity, self-rated health, and sick days.

Methods: This cross-sectional study included 619 Black older adults residing in South Los Angeles. Data on demographic factors (age and gender), socioeconomic characteristics, economic strain, health insurance, living arrangement, marital status, health behaviors, depressive symptoms, pain intensity, number of chronic diseases, sick days, and self-rated health were collected. Five linear regressions were used to analyze the data.

Results: Although high education was associated with less economic strain, it was the economic strain, not educational attainment, which was universally associated with depressive symptoms, pain intensity, self-rated health, chronic diseases, and sick days, independent of covariates. Similar patterns emerged for all health outcomes suggesting that the risk associated with economic strain and lack of health gain due to educational attainment are both robust and independent of type of health outcome.

Conclusion: In economically constrained urban environments, economic strain is a more salient social determinant of health of Black older adults than educational attainment. While education loses some of its protective effects, economic strain deteriorates health of Black population across domains. There is a need for bold economic and social policies that increase access of Black communities to cash at times of emergency. There is also a need to improve the education quality in the Black communities.

\section{Background}

Socioeconomic status (SES) indicators such as educational attainment and economic strain are among the strongest social determinants of health ${ }^{1-5}$. Link, Phelan, Mirowsky, Ross, Hayward, Williams, and many other prominent scholars have provided empirical and theoretical evidence regarding the protective effects of SES indicators such as education and economic strain on health across cohorts ${ }^{1-4,6-15}$. Educational attainment is a strong SES indicator and social determinant of health of both young ${ }^{16}$ and older adults ${ }^{17}$. Low educational attainment is also one of the drivers of racial health disparities ${ }^{18}$. 
Socioeconomic factors, particularly educational attainment, however, do not similarly impact the health of different racial groups ${ }^{11,12,19}$. The gradient of the effect of educational attainment on mortality risk may be flatter for Blacks than Whites ${ }^{11,12}$. Due to discriminatory preferences and practices of the labor market, education levels better translate to high-quality jobs for Whites than Blacks. Thus, Blacks remain at low-status jobs even when they attain a high education ${ }^{20,21}$. As a result of such discrimination, high educational attainment tends to generate fewer positive health outcomes for Blacks than Whites 20,22-24. $^{2}$

Economic strain can be defined as worries related to not having sufficient economic resources to make ends meet, pay the bills, etc. Economic strain reflects an aspect of SES that is not covered by conventional SES indicators such as education and income ${ }^{25}$. Economic strain may have more significant effects on the health of Black communities ${ }^{25}$. Economic strain may become particularly detrimental in contexts that are poor in other resources (e.g., economic constraints ${ }^{25}$. Previous research has shown that perceived SES, but not education, increases the vulnerability of Blacks to discrimination ${ }^{25}$. While research shows that High SES may become positively correlated with discrimination and depression for Blacks ${ }^{25-28}$, economic strain becomes a unique marker of $\mathrm{SES}^{25}$. This is because while education increases access to resources, italso increases psychological vulnerability to racism among the Black community ${ }^{28-31}$ as people may become more aware of the glass ceiling and inequalities at high SES levels.

Economic strain is probably one of the most essential SES indicators for the Black communities ${ }^{25}$. In both the general population of older adults ${ }^{32,33}$ and individuals with chronic diseases ${ }^{34}$, economic strain closely reflects poor health ${ }^{35}$. Economic strain is linked to poor $\operatorname{diet}^{36}$, smoking $^{37}$, alcohol use $^{38}$, suicide ${ }^{39}$, and depression ${ }^{40}$. Economic strain is a specific type of stress and increases oxidative stress ${ }^{41}$. It limits available pro-health behaviors and choices that are needed to maintain one's health ${ }^{32}$. Economic strain limits access to and use of health care services $^{32}$. Individuals under great economic strain report poor self-rated health ${ }^{35}$. Economic strain also increases the risk of various types of chronic diseases ${ }^{42}$, such as heart disease $^{42}$, diabetes ${ }^{34}$, and cancer ${ }^{43,44}$. Economic strain also deteriorates disease management ${ }^{34}$.

Various SES indicators may have joint and unique health implications for racial minorities. As suggested by the Minorities' Diminished Returns (MDRs) theory ${ }^{45}$, education shows smaller health effects for marginalized people such as Blacks ${ }^{20-24,46}$. That is highly educated Blacks remain at high risk of poor health ${ }^{20,24,25,46-49}$. Such patterns are observed in Black youth, adults, and older adults. These studies cumulatively suggest that objective SES indicators such as education may have "less than expected" effects on the well-being and health of Black older adults, while economic strain may have an exacerbated effect for the very same population ${ }^{25,51}$. However, we are only aware of one study simultaneously comparing the effects of educational attainment and economic strain on the well-being and health of Black older adults.

In such conditions, while education shows weaker effects ${ }^{45}$, economic strain may be particularly impactful on populations that have low access to buffers such as social support, which is common in old age ${ }^{33}$. As a result, research has documented major adverse health effects of economic strain for Blacks ${ }^{40,52,53}$ and older adults ${ }^{54-56}$. For example, in one study in a Black community, economic strain at baseline predicted future heart disease ${ }^{42}$. These adverse effects of economic strain in the elderly may be compounded by unemployment, social isolation, lack of access to transportation, and various chronic diseases.

In a recent study ${ }^{57}$, economic strain was positively associated with chronic diseases, chronic pain, self-rated health, depressive symptoms, and sick days. Although this study suggested that economic strain seems to be linked to self-rated health, sick days, chronic pain, chronic diseases, and depressive symptoms, this study did not compare the role of economic strain and educational attainment. The authors of that study advocated for the evaluation of social determinants of health in providing health care of Black older adults. However, the study did not control for several confounders. In fact, the results were based on zero-order or partial correlations and multivariable analysis that can investigate the joint effects of educational attainment and economic strain on mental and physical health outcomes while other confounders are controlled.

Aims

The current study investigated additive effects of educational attainment and economic strain on five health outcomes, namely depressive symptoms, pain intensity, chronic diseases, self-rated health, and sick days, for Black older adults in the underserved areas of South Los Angeles. The hypothesis was that educational attainment would have a small protective effect, while economic strain will show a considerable risk effect in our sample. We expected the very same pattern across health outcomes ${ }^{58}$ for the combined effects of education and economic $\operatorname{strain}^{59-61}$. That is, we expect that in contexts with high economic constraints, economic strain will operate as a risk while education will fail to show considerable protective effects. This hypothesis is in line with the observation that racism limits the health gains that follow educational attainment ${ }^{20,22,23,45,47-49,62-65}$.

\section{Methods}

\section{Design}

This cross-sectional household survey was conducted in South Los Angeles 2015-2018. The study was initially 
conducted to investigate medication-related challenges of Black older adults ${ }^{6-69}$. The interview collected data on demographic factors, SES characteristics (education and economic strain), health insurance, living arrangement, marital status, depressive symptoms, pain intensity, chronic diseases, self-rated health, and sick days. While the full evaluation took up to 4 hours, the structured faceto-face interview lasted about 2 hours. Interviews were performed by a physician or a nurse.

\section{Participants and Sampling}

The study recruited a convenience sample of Black older adults. Participants were recruited from predominantly Black housing units and senior centers that were located in South Los Angeles. Participants were Black or African American, non-institutionalized people, all age 65 years or older. All participants had hypertension.

The original study, which was conducted to examine medication-related challenges in Blacks with hypertension, included a total number of 740 Blacks aged 55 years and older. However, in the current study, we exclusively focused on participants that were $65+$ years of age $(n=619)$. No institutionalized participant was enrolled from skilled nursing facilities. Considerable cognitive deficits or current enrollment in a clinical trial were exclusion criteria.

\section{Institutional Review Board}

The protocol of the current investigation was approved by the institutional review board at the Charles R. Drew University of Medicine and Science. All participants signed consent before enrollment in this study.

\section{Study Measures}

Study variables in this analysis included demographic factors (i.e., gender and age), objective SES (i.e., educational attainment), living arrangement, marital status, health insurance, economic strain, depressive symptoms, pain intensity, chronic diseases, self-rated health, and sick days.

Demographic Factors: Gender and age were entered as demographic covariates. Age was an interval variable, operationalized as a continuous measure. Gender was a dichotomous variable.

Living Arrangement. Participants were asked if they were living alone or whether there were any other family members or a partner living with them. Living arrangement is a strong determinant of health among older adults ${ }^{70}$.

Marital Status: Participants' marital status was coded as non-married $=0$ and married $=1$.

Health Insurance Status: Participants were asked about their health insurance coverage. Health insurance status was a dichotomous variable that reflected health insurance (0/1). We considered being covered by Medicare, Medicaid, VA, non-federal health insurance, or private insurance as having health insurance. As only six individuals did not have health insurance, we did not include health insurance in our multivariable linear regression model.

Health Behaviors: Participants reported if they were smoking cigarettes and whether they were drinking alcohol. These two variables were conceptualized as dichotomous variables.

Objective Socioeconomic Status (SES): Education attainment was the only measure of objective SES. Education was an interval variable (years of schooling) with a higher score indicating more educational attainment.

Economic Strain: Self-reported (perceived) economic strain was measured using three items that were in line with Pearlin's list of main chronic economic strains that are being experienced by low SES individuals ${ }^{71-73}$. These items assess whether self-reported money is sufficient to meet essential needs (food, clothes, mortgage, bills). The items also measured the frequency of not having enough money to buy enough food, clothing, and paying bills. Responses were on a 0 to 5 scale, with responses ranging from 'never' to 'always'(with 0 signifying "never" and five signifying "always"). A total score was calculated with a high score reflecting more economic strain. Reliability of the measure was excellent with a Cronbach alpha $=.923$.

Symptoms of Depression: This study used the 15 itemShort Geriatric Depression Scale to evaluate symptoms of depression ${ }^{74-87}$. Responses were on a "yes" or "no" scale. The depressive symptoms sum score ranged between 0 and 15 with higher scores suggestive of the presence of more severe symptoms of depression. The Geriatric Depression Scale -Short form has acceptable validity and reliability. This measure has been frequently used in community and clinical settings ${ }^{74-87}$.

Pain Severity: We measured the intensity of pain using four subscales of the McGill Pain Questionnaire- ShortForm $2^{88}$. During a face-to-face interview, respondents responded to 22 questions on the extent of experiencing various types of pain over the past seven days. Items were on an 11-point numeric rating scale from 0 to 10 (none to worst possible). Our total pain score was calculated based on mean score of all items ${ }^{88-94}$. A higher score is indicative of more pain intensity.

Chronic Diseases: Participants were asked about 11 chronic diseases. Participants reported if a physician or a healthcare provider has ever told them that they have any of the following chronic diseases: asthma, chronic obstructive pulmonary disease, diabetes, hypertension, heart disease, lipid disorder, thyroid disorder, cancer, osteoarthritis, rheumatoid arthritis, and gastrointestinal disease. While self-reported chronic diseases is valid ${ }^{95-97}$, 
some bias should be expected due to underreporting of some conditions.

Self-Rated Health: Participants' self-rated health was assessed by a single-item health measure with five options ${ }^{64,98-105}$. The item reads, "In general, would you say your health is: "very good," "good," "fair," "bad," and "very bad." Responses were on an interval variable ranging from one to five, with a high score indicating poor selfrated health. Poor self-rated health predicts the risk of mortality ${ }^{64,98-105}$.

Sick Days: A single item which read "In the past 12 months, how frequently have you been sick?" was used to assess sick days in the past year. The responses ranged from never (coded as 1) to always (coded as 5). A higher score indicated a higher number of sick days. This measure is commonly applied in previous studies ${ }^{106-108}$.

\section{Statistical Analysis}

We used SPSS 23.0 for data analysis. To describe the sample, we reported frequency (n), relative frequency (\%), mean, and standard deviation (SD). We used the Pearson correlation test for our bivariate analysis. We applied linear regression models with health outcomes as the dependent variable, educational attainment, and economic strain as the independent variables, and age, gender, marital status, and living arrangements were the covariates. Give that only six participants did not report having some types of health insurance; we did not include this variable in our multiple linear regression models. We reported unstandardized $b$, standard error (SE), 95\% confidence intervals (95\% CI), and level of $p$ values.

\section{Results}

Table 1 shows a summary of all study variables in the pooled sample. Most participants were female (65.3\%) and were living alone $(59.9 \%)$. Only a small percentage were married (14.2\%). Almost all participants reported having health insurance (99\%). On average, participants were 74.0 years old.

Table 2 shows the results of zero-order correlations using Pearson correlation test. Higher educational attainment

Table 1: Descriptive Statistics

\begin{tabular}{|l|c|c|}
\hline \multicolumn{1}{|c|}{ All } & \\
\hline Gender & $\boldsymbol{n}$ & $\%$ \\
\hline Female & 404 & 65.3 \\
\hline Male & 215 & 34.7 \\
\hline Married & & \\
\hline No & 531 & 85.8 \\
\hline Yes & 88 & 14.2 \\
\hline Living Alone & & \\
\hline No & 248 & 4.1 \\
\hline Yes & 371 & 59.9 \\
\hline Health Insurance (Any) & & \\
\hline No & 6 & 1.0 \\
\hline Yes & 613 & 99.0 \\
\hline Smoking & & \\
\hline No & 523 & 84.5 \\
\hline Yes & 96 & 15.5 \\
\hline Drinking & & \\
\hline No & 433 & 7.0 \\
\hline Yes & 186 & 3.0 \\
\hline & Mean & SD \\
\hline Age (Years) & 74.0 & 7.0 \\
\hline Educational Attainment (Years) & 12.7 & 2.4 \\
\hline Economic strain & 8.2 & 4.9 \\
\hline Depressive Symptoms & 2.1 & 2.4 \\
\hline Pain Intensity & 1.8 & 2.1 \\
\hline Chronic diseases & 3.1 & 1.9 \\
\hline Self-Rated Health & 2.4 & 1.0 \\
\hline Sick Days & & \\
\hline ( & & \\
\hline Standard & & \\
\hline
\end{tabular}

SD: Standard Deviation

Table 2: Bivariate correlations (Pearson correlation)

\begin{tabular}{|c|c|c|c|c|c|c|c|c|c|c|c|c|c|}
\hline & 1 & 2 & 3 & 4 & 5 & 6 & 7 & 8 & 9 & 10 & 11 & 12 & 13 \\
\hline 1 Age (Years) & 1.00 & $-.20^{* *}$ & $-.10^{*}$ & -.04 & $.10^{*}$ & -.01 & $-.23^{* *}$ & $-.08^{*}$ & .02 & $-.16^{* *}$ & $-.11^{* *}$ & $-.10^{*}$ & $-.12^{* *}$ \\
\hline 2 Educational Attainment (Years) & & 1.00 & $-.13^{* *}$ & .06 & -.03 & .08 & $-.28^{* *}$ & $-.16^{* *}$ & $-.09^{*}$ & -.03 & .00 & -.07 & -.03 \\
\hline 3 Financial Difficulty & & & 1.00 & $-.09^{*}$ & $.15^{* *}$ & .01 & -.02 & .05 & $.22^{* *}$ & $.18^{* *}$ & $.13^{* *}$ & $.31^{* *}$ & $.29^{* *}$ \\
\hline 4 Married & & & & 1.00 & $-.41^{* *}$ & -.01 & $.15^{* *}$ & $.15^{* *}$ & -.02 & $-.09^{*}$ & .00 & -.05 & -.07 \\
\hline 5 Living Alone & & & & & 1.00 & -.01 & .04 & -.07 & .07 & .06 & .04 & $.14^{* *}$ & $.14^{* *}$ \\
\hline 6 Health Insurance & & & & & & 1.00 & -.03 & .07 & .05 & -.01 & -.01 & .03 & .01 \\
\hline 7 Smoking & & & & & & & 1.00 & $.27^{* *}$ & .02 & $.17^{* *}$ & -.07 & $.18^{* *}$ & $.08^{*}$ \\
\hline 8 Drinking & & & & & & & & 1.00 & -.02 & .07 & .03 & .07 & $.12^{* *}$ \\
\hline 9 Chronic diseases & & & & & & & & & 1.00 & $.27^{* *}$ & $.27^{* *}$ & $.32^{* *}$ & $.44^{* *}$ \\
\hline 10 Self-Rated Health & & & & & & & & & & 1.00 & $.23^{* *}$ & $.30^{* *}$ & $.37^{* *}$ \\
\hline 11 Sick Days & & & & & & & & & & & 1.00 & $.27^{* *}$ & $.33^{* *}$ \\
\hline 12 Depressive Symptoms & & & & & & & & & & & & 1.00 & $.41^{* *}$ \\
\hline 13 Pain Intensity & & & & & & & & & & & & & 1.00 \\
\hline
\end{tabular}

${ }^{*} p<.05 \quad{ }^{* *} p<.01$ 
was correlated with lower levels of economic strain ( $\mathrm{r}=$ $-.13, \mathrm{p}<.05$ ). Economic strain was positively correlated with worse status of all health outcomes ( $r$ ranging between .13 and $.31, \mathrm{p}<.05)$. Educational attainment was negatively correlated with the number of chronic diseases $(r=-.09, p$ $<.05$ ) but not with any of the other four health outcomes (p $>$.05). All health problems were positively correlated with each other ( $\mathrm{r}$ ranging between .33 and $.44, \mathrm{p}<.05$ ).

Table 3 shows the results of five linear regression models, one for each health outcome. In all these models, educational attainment and economic strain were the independent variables, a health outcome was the dependent variable, and age, gender, marital status, living arrangement, and health behaviors (smoking and drinking) were the covariates. These models suggest that economic strain, but not educational attainment, was associated with depressive symptoms, pain intensity, number of chronic diseases, self-rated health, and sick days. Similar patterns emerged regardless of health outcome.

\section{Discussion}

The current study explored how educational attainment and economic strain are associated with five health outcomes, namely depressive symptoms, pain intensity, number of chronic diseases, self-rated health, and frequency of sick days in Black older adults residing in economically disadvantaged areas of South Los Angeles. The results suggested that while educational attainment failed to protect them, high economic strain was associated with various poor health outcomes among Black older adults. Based on these results, we advocate for increased policies and programs that can stabilize incomes for Black populations across the life span.

As limitations should be in mind before the results are interpreted, we start our discussion with a review of the limitations of the current study. First, our cross-sectional design does not allow any causal inferences. Our results suggest association rather than causation. Second, there were some omitted SES indicators such as income and wealth. Given the sensitivity of economic and financial information and large amounts of missing data regarding income and wealth due to lack of disclosure ${ }^{109}$, and even low reliability of these variables in simple interviews ${ }^{110}$, we did not collect data on such sensitive information ${ }^{111}$. Future research should go beyond measuring education and economic strain and also measure income and wealth. Third, the sample was convenient. Thus, the results are not generalizable to all Black older adults in the US. Despite these limitations, the current study extends the limited existing knowledge on social determinants of physical and mental health of Black older adults in low-income urban settings.

In line with our hypotheses, educational attainment did not affect chronic diseases, self-rated health, sick days, depression, or pain. Similar smaller effects of SES were found on self-rated health ${ }^{20,46}$, depression ${ }^{60,63}$, and chronic

Table 3: Summary of five linear regression models with depressive symptoms, pain intensity, chronic diseases, self-rated health, and sick days as outcomes

\begin{tabular}{|c|c|c|c|c|c|c|}
\hline \multirow[b]{2}{*}{ Depressive Symptoms } & \multirow[t]{2}{*}{ B } & \multirow[t]{2}{*}{ SE } & \multicolumn{2}{|c|}{$95 \% \mathrm{Cl}$} & \multirow[t]{2}{*}{$\mathbf{t}$} & \multirow[t]{2}{*}{$\mathbf{P}$} \\
\hline & & & & & & \\
\hline Gender (Female) & .08 & .20 & -.32 & .48 & .41 & .681 \\
\hline Age (Years) & -.02 & .01 & -.05 & .01 & -1.55 & .121 \\
\hline Educational Attainment (Years) & -.04 & .04 & -.13 & .04 & -1.09 & .278 \\
\hline Financial difficulty & .13 & .02 & .09 & .17 & 6.66 & $<.001$ \\
\hline Marital (Married) & .09 & .29 & -.48 & .67 & .31 & .757 \\
\hline Living Arrangement (living alone) & .57 & .21 & .16 & .98 & 2.71 & .007 \\
\hline Smoking & .89 & .28 & .34 & 1.45 & 3.17 & .002 \\
\hline Alcohol Use & -.08 & .21 & -.50 & .34 & -.37 & .713 \\
\hline \multicolumn{7}{|l|}{ Pain Intensity } \\
\hline Gender (Female) & .42 & .18 & .07 & .76 & 2.37 & .018 \\
\hline Age (Years) & -.03 & .01 & -.06 & -.01 & -2.55 & .011 \\
\hline Educational Attainment (Years) & -.03 & .04 & -.10 & .04 & -.81 & .418 \\
\hline Financial difficulty & .10 & .02 & .07 & .14 & 6.15 & $<.001$ \\
\hline Marital (Married) & .02 & .25 & -.48 & .52 & .06 & .949 \\
\hline Living Arrangement (li & .42 & .18 & .06 & .78 & 2.31 & .021 \\
\hline Smoking & .13 & .24 & -.35 & .61 & .51 & .607 \\
\hline Alcohol Use & .32 & .18 & -.05 & .68 & 1.72 & .086 \\
\hline \multicolumn{7}{|l|}{ Chronic diseases } \\
\hline Gender (Female) & .47 & .16 & .16 & .79 & 2.93 & .004 \\
\hline Age (Years) & .00 & .01 & -.02 & .03 & .30 & .765 \\
\hline Educational Attainment (Years) & -.07 & .03 & -.13 & .00 & -1.95 & .052 \\
\hline Financial difficulty & .08 & .02 & .05 & .11 & 5.27 & $<.001$ \\
\hline Marital (Married) & .17 & .23 & -.29 & .63 & .75 & .456 \\
\hline Living Arrangement (living alone) & .17 & .17 & -.16 & .50 & 1.02 & .306 \\
\hline Smoking & .15 & .22 & -.29 & .59 & .66 & .508 \\
\hline Alcohol Use & -.18 & .17 & -.51 & .15 & -1.07 & .286 \\
\hline \multicolumn{7}{|l|}{ Self-Rated Health } \\
\hline Gender (Female) & .20 & .08 & .03 & .36 & 2.31 & .021 \\
\hline Age (Years) & -.02 & .01 & -.03 & -.01 & -3.07 & .002 \\
\hline Educational Attainment (Years) & -.02 & .02 & -.05 & .01 & -1.12 & .265 \\
\hline Financial difficulty & .03 & .01 & .01 & .04 & 3.21 & .001 \\
\hline Marital (Married) & -.17 & .12 & -.41 & .07 & -1.39 & .165 \\
\hline Living Arrangement (living alone) & .06 & .09 & -.11 & .23 & .68 & .495 \\
\hline Smoking & .38 & .12 & .15 & .61 & 3.21 & .001 \\
\hline Alcohol Use & -.01 & .09 & -.18 & .17 & -.07 & .946 \\
\hline \multicolumn{7}{|l|}{ Sick days } \\
\hline Gender (Female) & .07 & .09 & -.11 & .24 & .74 & .461 \\
\hline Age (Years) & -.01 & .01 & -.03 & .00 & -2.37 & .018 \\
\hline Educational Attainment (Years) & .00 & .02 & -.04 & .03 & -.15 & .884 \\
\hline Financial difficulty & .02 & .01 & .01 & .04 & 2.85 & .005 \\
\hline Marital (Married) & .05 & .13 & -.20 & .31 & .40 & .689 \\
\hline Living Arrangement (living alone) & .09 & .09 & -.09 & .28 & 1.00 & .317 \\
\hline Smoking & .14 & .12 & -.10 & .39 & 1.14 & .256 \\
\hline Alcohol Use & -.17 & .09 & -.35 & .02 & -1.77 & .078 \\
\hline
\end{tabular}

b: Unstandardized regression coefficient; SE: Standard Error; $\mathrm{Cl}$ : Confidence Interval 
diseases ${ }^{46,47}$. We, however, are not aware of any previous studies showing the same pattern for pain. Besides, most of the previous findings are in children ${ }^{45,46,48,49}$ and adults $^{20,46,62}$, and very few previous studies have shown the same patterns for older adults ${ }^{50}$. Thus, two innovations of these results are to expand the literature, which is mostly on youth and adults, to older adults, and also document the same patterns for pain intensity. Finally, while most previous findings are on national samples ${ }^{20,47,62}$, the current study suggests that similar patterns hold at a local level ${ }^{46,65}$.

In the absence of a protective effect of education, the health and well-being of Black individuals seem to be strongly impacted by economic strain. Previous research has shown the role of economic strain as a significant threat to the health of the Black communities ${ }^{40,52,53}$, particularly for Black older adults ${ }^{54-56}$. While economic strain limits people's options for health-supporting behaviors and access to resources and services ${ }^{32}$, it also operates as a source of psychological stress ${ }^{41}$. Economic strain increases the risk of mortality ${ }^{19,112-115}$. This increased risk may be due to an increased risk of a wide range of chronic diseases ${ }^{42}$ including but not limited to heart disease ${ }^{114}$, diabetes ${ }^{34}$, cancer $^{113}$, hypertension ${ }^{42}$, poor self-rated health ${ }^{35}$, or mental health problems such as anxiety ${ }^{43,116}$, depression ${ }^{40,51}$ and suicide ${ }^{39}$. Economic strain also increases behavioral risk, such as poor diet ${ }^{36}$, smoking $^{37}$, and alcohol use ${ }^{38}$.

Economic strain is shown to be one of the most influential social determinants of health ${ }^{35,117-125}$. This effect is shown for the general population ${ }^{126}$, people with chronic diseases $^{34}$, and older adults ${ }^{32}$. Economic strain becomes a stronger threat for Black older adults who lack social support and other potential buffers ${ }^{33}$. Loneliness and lack of access to buffers seem to be a common element of aging in Black communities ${ }^{33}$.

In the US, Black older individuals with a more economic strain experience worse health outcomes across all domains. This finding is not new as economic strain is a reliable SES indicator impacting various aspects of health in multiple studies ${ }^{40,112,127,128}$. Also referred to as financial difficulty, stress, distress, or hardship ${ }^{41,43,54,129}$, economic strain reflects a lack of resources, particularly the absence of liquid expendable income. Individuals under economic strain are unable to access and use services that they need, maintain pro-health behaviors, or access resources that buffer stress and illness when they occur ${ }^{32,55}$.

Economic strain showing a harmful effect while education not showing a protective effect might be due to the economically constrained nature of low-income urban areas that are limited in resources. We found that economic strain shows consistent effects as identical patterns emerge across health outcomes. At the same time, highly educated and low educated Black older adults show the very same risk of depressive symptoms, pain intensity, chronic diseases, poor self-rated health, and sick days, which is in line with the MDRs of education in resourcelimited settings ${ }^{130,131}$.

Educational attainment's failure to protect Black older adults against health problems may be due to high segregation and concentration of poverty in urban Black communities. Lack of protective effects of educational attainment in marginalized people, also called MDRs, has been attributed to structural racism and social stratification ${ }^{20,22,23,47,62,63}$. This finding may also be attributed to five specific reasons: (a) poor quality of education in these communities, as discussed by Jenifer Manley ${ }^{132-137}$, (b) most Black older adults being out of the labor market (labor market carries some of the health gains of education attainment), (c) most Black older adults have some insurance, which covers their health needs regardless of their education, (d) absence of prestigious high paying jobs in urban settings, and (e) high education may increase psychological vulnerability of Blacks to racism, which reduces its protective effects. Some research has shown that high education may predict undesired mental health outcomes for Black individuals ${ }^{26-30,63,138,139}$. Opposite to the pattern seen for Blacks, educational attainment always translates to better health for Whites ${ }^{1-4}$.

Economic strain is closely linked to perceived stress $^{33,112,140}$. Thus, as shown by past research ${ }^{25}$, economic strain may have stronger effects on Black older adults than hard SES indicators such as income or education ${ }^{25}$. This might also be because perceived economic strain, depression, and perceived health have affective valence and component (i.e., tone/shade) ${ }^{51,141-143}$.

Although education is known as a strong determinant of health ${ }^{1-4}$, and as low education is believed to be a fundamental cause of racial health disparities ${ }^{18}$, education has differential implications across various social groups. While the most socially privileged groups gain the most amount of health from their education, this gain tends to zero for the least privileged groups ${ }^{64,144}$. That is, while education is commonly shown to improve health, crossracial variations exist in the health effects of education ${ }^{1-4,6-14}$. Overall, while educational attainment improves health through multiple mechanisms, including promoting lifestyle $^{16}$ for many populations including the elderly ${ }^{17}$, there is considerable evidence suggesting that educational attainment may lose some of its health effects for Black communities $20-24,46$.

In line with the MDRs theory, the inner strength of this manuscript is questioning the presumption that educational attainment should result in a protective (or positive) effect on a person's health, long-term. We argue that embedded in this presumption is the "bootstrap" philosophy that hard 
work (and investment on human capital) will pay off for all citizens, regardless of race or ethnicity, and translate into health as well as economic and financial security through educational pursuits that translate into job opportunities. Nevertheless, as shown by this study and the rest of the MDRs literature, these effects are not equitably distributed across all race/ethnic groups in our society. Socioeconomic factors do not similarly promote the health and wellbeing of Blacks and Whites ${ }^{11,12}$. The magnitude of the effects of each additional year of schooling on health outcomes is smaller for Blacks than Whites ${ }^{11,12}$. The threshold (i,e, stepwise) effect of educational credentials is also weaker for Blacks than Whites because the US labor market gives lower status jobs to Blacks than Whites ${ }^{20,21}$. In the US, it is race and SES, not race or SES, that shape health ${ }^{145-147}$.

Aurora Jackson has conducted extensive work on economic strain, low paying jobs, unemployment, and how such conditions influence the daily lives of Blacks, particularly Black women ${ }^{148,149}$. So has work by Hamilton and Darity on the wealth gap and economic conditions of Black families. They have proposed reparation and baby bonds as potential solutions to the weatlh inequality of Blacks ${ }^{150-152}$. Lincoln has also conducted studies on the interplay between various sources of stress, such as economic strain in Blacks ${ }^{153-155}$. The work of Oliver and Shapiro also has helped us understand the wealth gap between Blacks and Whites ${ }^{156,157}$.

The work by Sherraden and Trina Shanks has helped us understand the life conditions associated with economic strain of low-income people, including Blacks ${ }^{158-160}$. Sherraden has tested innovations to improve the social and economic well-being of low-income families, including Blacks. He has proposed policies that may promote inclusion in asset building for marginalized people. One example of such asset-based policies and programs in the US is progressive child development accounts. In particular, they discuss the findings from the SEED for Oklahoma Kids study, which is a large-scale randomized statewide policy experiment that deposited $\$ 1,000$ into state-owned Oklahoma 529 College Savings Plan (OK 529) accounts for 1,358 children. Although Sherraden's work is on children and not older adults, his work is still relevant to our finding as it addresses the critical aspect of the discussion and implication section, which is providing financial incentives. These lines of work collectively suggest safety nets and economic policies that may help Black families and communities accumulate wealth and buffer the effect of deep poverty ${ }^{159-163}$. Other studies have also shown positive health effects of reducing economic strain ${ }^{164}$.

As this study showed, economic strain and education have very different effects on the health of disadvantaged racial and ethnic groups such as urban Black older adults who struggle with poverty while affected by multiple chronic diseases. Similar patterns are shown by research for other sections of the Black communities ${ }^{20-24,46}$ as well as Hispanics $^{62,65}$, Native Americans ${ }^{165}$, and other marginalized groups $^{166}$. The widespread and systemic nature of MDRs suggest MDRS are not innate or biological, but rather a function of racism, prejudice, and resource-scarce areas. Although MDRs of education are not specific to Blacks, but rather to any marginalized group, , given the harsh living conditions of Blacks in poor urban areas, Minorities' Diminished Returns ${ }^{45}$ may be more pronounced in Blacks $^{20,24,25,46-49}$.

Lack of wealth and economic reserve contribute to the vulnerability of Black older adults to economic strain and lack of cash $^{14,117,167-176}$. Being Black is associated with a hidden tax to the middle class. Due to some historical reasons, Blacks have extremely low levels of wealth. Slavery, redlining, Jim Crow laws, discriminatory lending, mass incarceration, war on crime, and many other policies have kept average Blacks poor ${ }^{177-183}$. Given such historical injustice, most Black families have not been able to accumulate wealth over time. Such wealth operates as a buffer in times of uncertainty when stress and hassles occur $^{172,174}$.

Excessive financial necessities continue to hurt the health of Black older adults in urban settings. Our findings suggest that policies that provide cash supply at the time of need may be promising as a strategy to tackle health disparities in urban areas where deep and chronic poverty compounds the health effects of multiple chronic diseases. Policy solutions to health disparities should go beyond health policies by including public and economic policies that address economic strain of Black older adults. A promising policy may be lending at the time of emergency.

Interestingly enough, the results reported here are quite consistent with a recent study conducted on older adults residing in a Central and Eastern European country. The authors also found that higher education was not enough to protect individuals against depressive symptoms, when adult socioeconomic position was taken into account. These findings may suggest that the lack of protective effects of education may be a pattern that hold for some populations within and outside the US ${ }^{184}$.

\section{Implications}

Economic strain is a social factor modifiable through economic policies (e.g., tax, social welfare, and income redistribution) as well as on-ground programs that can be delivered to the communities (e.g., free tax preparation programs, financial empowerment services, and emergency funds). Reducing economic strain remains a hopeful public policy solution that can reduce or eliminate health inequalities of Blacks in urban areas ${ }^{150-152}$.

What education can do in economically constrained 
urban areas is very limited ${ }^{185-191}$. In such a context, a lack of liquid assets (i.e., cash) becomes very detrimental. Economists Hamilton and Darity have proposed baby bonds as a potential solution to prevent economic strain among the next generation of Blacks. Baby bonds are trust accounts of up to $\$ 60,000$ for every newborn, which are calibrated to the family's wealth. This bond can help generate the required seed money for buying a home, starting a business, or help at the time of highest financial need. Another proposed solution by the same scholars is reparations as a potential solution to the wealth inequality of Blacks. These economic policies are specific proposals that, if written as the law can impact society and have significant national health effects as they effectively increase economic security for the Black community ${ }^{164}$. These bold and innovative economic proposals (e.g., reparation, baby bonds, etc.) may be an effective way to reduce economic as well as health inequalities in the US. Writing these economic interventions as law and policies may be a stable solution to tackling health disparities in low-income Black communities.

Although multiple policy solutions can be brought to the table, here we discuss a relevant economic policy that can potentially buffer the effect of economic strain on lowincome Black communities. Income redistribution policies that increase the access of two-income people to cash that can be used to pay bills and buy food are critical $^{115,192,193}$. The challenge is that such policies are not viewed positively in the US, given the over-emphasis of American culture on meritocracy (i.e., relying on bootstraps).

To more effectively bring social justice and equity to the public discourse and law, Blacks should gain more political power, so they get a louder voice and their agenda can be written as law ${ }^{115,192,193}$. Although Blacks need to gain a stronger voice in the US political system, they are affected by poverty and related illnesses. That means the very same people who are supposed to solve the problem are disappearing faster and younger, because of poor healthrelated to poverty. In other words, the ones who need the change most do not get the chance to influence policy as they die earlier. Research shows that early mortality of Blacks results in a missed opportunity to correct the policies that can fix the problem of poverty among Blacks ${ }^{115,192,193}$.

Beyond the policies mentioned, such as reparations, baby bonds, and savings accounts for children, there is also a need for local services that are delivered at the community level to provide support for economic and financial security, especially for older Blacks. Although these policies are possible solutions, they are mainly early childhood methods that may ameliorate economic strain later in life. At the same time, there is a need for a range of solutions where we do not need to wait 70 years to see results of early childhood policy interventions. Another challenge is the likelihood of reparations in the current political climate. Although the need exists and the rationale clear, but these policy solutions may not be viable solutions for older adults, today.

To solve the current problems, safety net public healthcare systems should continue increasingly establishing co-located services (through Social Determinants of Health), and shared interagency centers should address nonmedical social needs, including financial and economic insecurity of individuals with multiple medical and social needs. Examples include free tax preparation programs that increase access to Earned Income Tax Credit and refunds and financial empowerment services that include onsite financial planning, budgeting, credit stabilization, under-banking, etc. In addition to emergency funds which have long existed through local government social service agencies, programs to address poverty concretely, and specifically for older adults, do exist in communities and should be mentioned as a viable way to serve older adults, particularly in underserved neighborhoods. Successful organizations that are on the ground and deliver services include Prosperity Now! and the NYC Department of Consumer Affairs, which is expanding its Financial Empowerment Centers across the city.

\section{Future Research}

It is still unknown whether elimination of economic strain through social and economic policies can be used as a sustainable policy to eliminate, or at least reduce, the existing racial gaps across health outcomes ${ }^{115,192,193}$. There are only a few previous attempts and social experiments to reduce the disparities in the health of Black communities by reducing economic strain. There is also a need to study why educational attainment has a "less than expected" health effects for Black older adults in general and particularly in low-income urban contexts.

There is a need for future research to differentiate the aspects that make all vs. Black older adults experience economic strain. Such research would require various ethnic groups, including Whites. Such research in diverse samples may be able to show how the effects of economic strain are compounded for all particularly, Black older adults. While most older adults are not working, and many are socially isolated and live alone, and a large proportion has health conditions. These effects may or may not differ between White and Black older adults, which needs more research. There is also a need to decompose the adverse health effects of economic strain from those of social isolation, aging, and comorbid health conditions. This research would suggest that if people are stabilized financially, their social isolation will still be a remaining risk operating in the background. 
There are some other variables that have not been taken into account in the current analysis. Among the most important missing variables are markers of early life socioeconomic position. Studies, however, have shown considerble amount of complexties, nuances, and heterogeneities in this regard. In one study, higher education of the mother was associated with better mental health (e.g. lower depressive symptoms) in older adults, independent of socioeconomic status in adulthood ${ }^{194}$. On the contrary, higher education of the father was associated with lower depressive symptoms in adulthood, but this association is explained by socioeconomic status in adulthood $^{194}$. In addition, no comparison group was used in this study, thus it is unknown whether the same results would be relevant to any non-Black group or not.

\section{Conclusion}

Economic strain may be more a more salient social determinant of the health of Black older adults than educational attainment, at least in economically constrained settings. This finding is in line with the literature on MDRs, which has repeatedly shown weaker than expected effects of educational attainment for Black people. Such diminishing returns may be due to structural factors such as social stratification, segregation, and systemic racism across levels and institutions which are embedded in U.S. society.

\section{Funding}

The mother study was supported by the Center for Medicare and Medicaid Services grant 1HOCMS331621. Additionally, Assari and Bazargan are supported by the NIH awards 5S21MD000103, 54MD008149, R25 MD007610, U54 TR001627, and 2U54MD007598,

\section{Disclosures}

The authors declare that they have no competing interests.

\section{Authors Contribution}

Shervin Assari: Conceptualization, data analysis, first draft of the manuscript, revision, approval of the final draft. Mohsen Bazargan: Conceptualization, design, funding acquisition, overseeing the study, revision, and approval of the final draft. Sharon Cobb: Conceptualization, revision of the paper, approval of the final draft.

\section{References}

1. Link BG, Phelan J. The social shaping of health and smoking. Drug Alcohol Depend. 2009; 104 Suppl 1: S6-10.

2. Link BG, Phelan J. Social conditions as fundamental causes of disease J Health Soc Behav. 1995; Spec No: 80-94.

3. Masters RK, Link BG, Phelan JC. Trends in education gradients of 'preventable' mortality: a test of fundamental cause theory. Soc Sci Med. 2015; 127: 19-28.
4. Phelan JC, Link BG, Tehranifar P. Social conditions as fundamental causes of health inequalities: theory, evidence, and policy implications. J Health Soc Behav. 2010; 51 Suppl: S28-40.

5. Rodriguez JM, Karlamangla AS, Gruenewald TL, et al. Social stratification and allostatic load: shapes of health differences in the MIDUS study in the United States. J Biosoc Sci. 2019; 1-18.

6. Mirowsky J, Ross CE. Education, Health, and the Default American Lifestyle. J Health Soc Behav. 2015; 56(3): 297-306.

7. Ross CE, Mirowsky J. Refining the association between education and health: the effects of quantity, credential, and selectivity. Demography. 1999; 36(4): 445-60.

8. Chiu CT, Hayward MD, Chan A, et al. Educational differences in the compression of disability incidence in the United States. SSM Popul Health. 2019; 7: 100347.

9. Crimmins EM, Saito Y, Kim JK, et al. Educational Differences in the Prevalence of Dementia and Life Expectancy with Dementia: Changes from 2000 to 2010. J Gerontol B Psychol Sci Soc Sci. 2018; 73(suppl_1): S20-S8.

10. Montez JK, Hayward MD, Brown DC, et al. Why is the educational gradient of mortality steeper for men? J Gerontol B Psychol Sci Soc Sci. 2009; 64(5): 625-34.

11. Montez JK, Hummer RA, Hayward MD. Educational attainment and adult mortality in the United States: a systematic analysis of functional form. Demography. 2012; 49(1): 315-36.

12. Montez JK, Hummer RA, Hayward MD, et al. Trends in the Educational Gradient of U.S. Adult Mortality from 1986 to 2006 by Race, Gender, and Age Group. Res Aging. 2011; 33(2): 145-71.

13. Montez JK, Zajacova A, Hayward MD. Disparities in Disability by Educational Attainment Across US States. Am J Public Health. 2017; 107(7): 1101-8.

14. Montez JK, Zajacova A, Hayward MD, et al. Educational Disparities in Adult Mortality Across U.S. States: How Do They Differ, and Have They Changed Since the Mid-1980s? Demography 2019.

15. Williams DR, Yan Y, Jackson JS, et al. Racial Differences in Physical and Mental Health: Socio-economic Status, Stress and Discrimination. J Health Psychol. 1997; 2(3): 335-51.

16. Hill TD, Needham BL. Gender-specific trends in educational attainment and self-rated health, 1972-2002. Am J Public Health. 2006; 96(7): 1288-92.

17. Kubzansky LD, Berkman LF, Glass TA, et al. Is educational attainment associated with shared determinants of health in the elderly? Findings from the MacArthur Studies of Successful Aging. Psychosom Med. 1998; 60(5): 578-85.

18. Levin S, Mayer-Davis EJ, Ainsworth BE, et al. Racial/ethnic health disparities in South Carolina and the role of rural locality and educational attainment. South Med J. 2001; 94(7): 711-8.

19. Bound J, Geronimus AT, Rodriguez JM, et al. Measuring Recent Apparent Declines In Longevity: The Role Of Increasing Educational Attainment. Health Aff (Millwood). 2015; 34(12): 2167-73.

20. Assari S, Moghani Lankarani M. Workplace Racial Composition Explains High Perceived Discrimination of High Socioeconomic Status African American Men. Brain Sci. 2018; 8(8).

21. Assari S, Preiser B, Kelly M. Education and Income Predict Future Emotional Well-Being of Whites but Not Blacks: A Ten-Year Cohort. Brain Sci. 2018; 8(7).

22. Assari S, Mistry R, Caldwell CH. Perceived Discrimination and Substance Use among Caribbean Black Youth; Gender Differences. Brain Sci. 2018; 8(7).

23. Assari S. Parental Educational Attainment and Mental Well-Being of College Students; Diminished Returns of Blacks. Brain Sci. 2018; 8(11). 
24. Assari S, Mistry R. Educational Attainment and Smoking Status in a National Sample of American Adults; Evidence for the Blacks Diminished Return. Int J Environ Res Public Health. 2018; 15(4).

25. Assari S, Preiser B, Lankarani MM, et al. Subjective Socioeconomic Status Moderates the Association between Discrimination and Depression in African American Youth. Brain Sci. 2018; 8(4).

26. Assari S, Gibbons FX, Simons R. Depression among Black Youth; Interaction of Class and Place. Brain Sci. 2018; 8(6).

27. Barbe MF, Massicotte VS, Assari S, et al. Prolonged high force high repetition pulling induces osteocyte apoptosis and trabecular bone loss in distal radius, while low force high repetition pulling induces bone anabolism. Bone. 2018; 110: 267-83.

28. Assari S, Lankarani MM, Caldwell CH. Does Discrimination Explain High Risk of Depression among High-Income African American Men? Behav Sci (Basel). 2018; 8(4).

29. Hudson DL, Bullard KM, Neighbors HW, et al. Are benefits conferred with greater socioeconomic position undermined by racial discrimination among African American men? J Mens Health. 2012; 9(2): 127-36.

30. Hudson DL, Neighbors HW, Geronimus AT, et al. Racial Discrimination, John Henryism, and Depression Among African Americans. J Black Psychol. 2016; 42(3): 221-43.

31. Hudson DL, Puterman E, Bibbins-Domingo K, et al. Race, life course socioeconomic position, racial discrimination, depressive symptoms and self-rated health. Soc Sci Med. 2013; 97: 7-14.

32. Pasco B. Impact of financial difficulty on health and aged care choices. Aust Nurs Midwifery J. 2016; 23(7): 30.

33. Aslund C, Larm P, Starrin B, et al. The buffering effect of tangible social support on financial stress: influence on psychological well-being and psychosomatic symptoms in a large sample of the adult general population. Int J Equity Health. 2014; 13(1): 85.

34. Morris JL, Chasens ER. Financial Difficulty: A Barrier to Self-care in Patients With Diabetes. Diabetes Educ. 2017; 43(3): 247-8.

35. Berry B. Does money buy better health? Unpacking the income to health association after midlife. Health (London). 2007; 11(2): 199226.

36. Klesges LM, Pahor M, Shorr RI, et al. Financial difficulty in acquiring food among elderly disabled women: results from the Women's Health and Aging Study. Am J Public Health. 2001; 91(1): 68-75.

37. Guillaumier A, Twyman L, Paul C, et al. Financial Stress and Smoking within a Large Sample of Socially Disadvantaged Australians. Int J Environ Res Public Health. 2017; 14(3).

38. Peirce RS, Frone MR, Russell M, et al. Financial stress, social support, and alcohol involvement: a longitudinal test of the buffering hypothesis in a general population survey. Health Psychol. 1996; 15(1): 38-47.

39. Carr MM, Ellis JD, Ledgerwood DM. Suicidality among gambling helpline callers: A consideration of the role of financial stress and conflict. Am J Addict. 2018; 27(6): 531-7.

40. Andrade FCD, Kramer KZ, Monk JK, et al. Financial stress and depressive symptoms: the impact of an intervention of the Chicago Earned Income Tax Periodic Payment. Public Health. 2017; 153: 99102.

41. Palta P, Szanton SL, Semba RD, et al. Financial strain is associated with increased oxidative stress levels: the Women's Health and Aging Studies. Geriatr Nurs. 2015; 36(2 Suppl): S33-7.

42. Medical Electronics Buyers Guide 1984, Part 6. CAT scanners, electrical safety \& test equipment, financial management, neonatal \& pediatric equipment, pulmonary/respiratory equipment, simulators, stress test systems/ergometers. Med Electron. 1984; 15(6): 116-92.
43. Sharp L, Carsin AE, Timmons A. Associations between cancerrelated financial stress and strain and psychological well-being among individuals living with cancer. Psychooncology. 2013; 22(4): 745-55.

44. Sharp L, O'Leary E, O'Ceilleachair A, etal. Financial Impact of Colorectal Cancer and Its Consequences: Associations Between Cancer-Related Financial Stress and Strain and Health-Related Quality of Life. Dis Colon Rectum. 2018; 61(1): 27-35.

45. Assari S, Caldwell CH, Zimmerman MA. Family Structure and Subsequent Anxiety Symptoms; Minorities' Diminished Return. Brain Sci. 2018; 8(6).

46. Assari S, Thomas A, Caldwell CH, et al. Blacks' Diminished Health Return of Family Structure and Socioeconomic Status; 15 Years of Follow-up of a National Urban Sample of Youth. J Urban Health. 2018; 95(1): 21-35.

47. Assari S. The Benefits of Higher Income in Protecting against Chronic Medical Conditions Are Smaller for African Americans than Whites. Healthcare (Basel). 2018; 6(1)

48. Assari S, Caldwell CH. Family Income at Birth and Risk of Attention Deficit Hyperactivity Disorder at Age 15: Racial Differences. Children (Basel). 2019; 6(1).

49. Assari S, Caldwell CH, Mincy R. Family Socioeconomic Status at Birth and Youth Impulsivity at Age 15; Blacks' Diminished Return. Children (Basel). 2018; 5(5).

50. Assari S, Lankarani MM. Education and Alcohol Consumption among Older Americans; Black-White Differences. Front Public Health. 2016; 4: 67.

51. Assari S. Race, Depression, and Financial Distress in a Nationally Representative Sample of American Adults. Brain Sci. 2019; 9(2).

52. Gyamfi P, Brooks-Gunn J, Jackson AP. Associations between employment and financial and parental stress in low-income single black mothers. Women Health. 2001; 32(1-2): 119-35.

53. Moran KE, Ommerborn MJ, Blackshear CT, et al. Financial Stress and Risk of Coronary Heart Disease in the Jackson Heart Study. Am J Prev Med. 2019; 56(2): 224-31.

54. Francoeur RB. Cumulative financial stress and strain in palliative radiation outpatients: The role of age and disability. Acta Oncol. 2005; 44(4): 369-81.

55. Hanratty B, Holland P, Jacoby A, et al. Financial stress and strain associated with terminal cancer--a review of the evidence. Palliat Med. 2007; 21(7): 595-607.

56. Logue BJ. Women at risk: predictors of financial stress for retired women workers. Gerontologist. 1991; 31(5): 657-65.

57. Evans MC, Bazargan M, Cobb S, et al. Mental and Physical Health Correlates of Financial Difficulties Among African-American Older Adults in Low-Income Areas of Los Angeles. Front Public Health. 2020; 8: 21.

58. Carter JD, Assari S. Sustained Obesity and Depressive Symptoms over 6 Years: Race by Gender Differences in the Health and Retirement Study. Front Aging Neurosci. 2016; 8: 312.

59. Assari S, Khoshpouri P, Chalian H. Combined Effects of Race and Socioeconomic Status on Cancer Beliefs, Cognitions, and Emotions. Healthcare (Basel). 2019; 7(1).

60. Assari S. Combined Racial and Gender Differences in the Long-Term Predictive Role of Education on Depressive Symptoms and Chronic Medical Conditions. J Racial Ethn Health Disparities. 2017; 4(3): 38596.

61. Assari S. Separate and Combined Effects of Anxiety, Depression and Problem Drinking on Subjective Health among Black, Hispanic and Non-Hispanic White Men. Int J Prev Med. 2014; 5(3): 269-79. 
62. Assari S. Socioeconomic Status and Self-Rated Oral Health; Diminished Return among Hispanic Whites. Dent J (Basel). 2018; 6(2).

63. Chalian H, Khoshpouri P, Assari S. Demographic, Social, and Behavioral Determinants of Lung Cancer Perceived Risk and Worries in a National Sample of American Adults; Does Lung Cancer Risk Matter? Medicina (Kaunas). 2018; 54(6).

64. Assari S. Life Expectancy Gain Due to Employment Status Depends on Race, Gender, Education, and Their Intersections. J Racial Ethn Health Disparities. 2018; 5(2): 375-86.

65. Assari S, Farokhnia M, Mistry R. Education Attainment and Alcohol Binge Drinking: Diminished Returns of Hispanics in Los Angeles. Behav Sci (Basel). 2019; 9(1).

66. Bazargan M, Smith J, Movassaghi M, et al. Polypharmacy among Underserved Older African American Adults. J Aging Res. 2017; 2017: 6026358.

67. Bazargan M, Smith J, Yazdanshenas $\mathrm{H}$, et al. Non-adherence to medication regimens among older African-American adults. BMC Geriatr. 2017; 17(1): 163.

68. Bazargan M, Smith JL, King EO. Potentially inappropriate medication use among hypertensive older African-American adults. BMC Geriatr 2018; 18(1): 238.

69. Bazargan M, Yazdanshenas H, Gordon D, et al. Pain in CommunityDwelling Elderly African Americans. J Aging Health. 2016; 28(3): 40325

70. Theeke LA. Sociodemographic and health-related risks for loneliness and outcome differences by loneliness status in a sample of U.S. older adults. Res Gerontol Nurs. 2010; 3(2): 113-25.

71. Laaksonen E, Lallukka T, Lahelma E, et al. Economic difficulties and physical functioning in Finnish and British employees: contribution of social and behavioural factors. Eur J Public Health. 2011; 21(4): 456-62.

72. Lallukka T, Ferrie JE, Kivimaki M, et al. Economic difficulties and subsequent sleep problems: evidence from British and Finnish occupational cohorts. Sleep Med. 2012; 13(6): 680-5.

73. Conklin AI, Forouhi NG, Suhrcke M, et al. Socioeconomic status, financial hardship and measured obesity in older adults: a crosssectional study of the EPIC-Norfolk cohort. BMC Public Health. 2013; 13: 1039.

74. Almeida OP, Almeida SA. [Reliability of the Brazilian version of the ++ abbreviated form of Geriatric Depression Scale (GDS) short form]. Arq Neuropsiquiatr. 1999; 57(2B): 421-6.

75. Bae JN, Cho MJ. Development of the Korean version of the Geriatric Depression Scale and its short form among elderly psychiatric patients. J Psychosom Res. 2004; 57(3): 297-305.

76. Bass DS, Attix DK, Phillips-Bute B, et al. An efficient screening tool for preoperative depression: the Geriatric Depression Scale-Short Form. Anesth Analg. 2008; 106(3): 805-9, table of contents.

77. Burke WJ, Roccaforte WH, Wengel SP. The short form of the Geriatric Depression Scale: a comparison with the 30-item form. J Geriatr Psychiatry Neurol. 1991; 4(3): 173-8.

78. Chiang KS, Green KE, Cox EO. Rasch analysis of the Geriatric Depression Scale-Short Form. Gerontologist. 2009; 49(2): 262-75.

79. Durmaz B, Soysal P, Ellidokuz H, et al. Validity and reliability of geriatric depression scale-15 (short form) in Turkish older adults. North Clin Istanb. 2018; 5(3): 216-20.

80. Ferraro FR, Chelminski I. Preliminary normative data on the Geriatric Depression Scale-Short Form (GDS-SF) in a young adult sample. J Clin Psychol. 1996; 52(4): 443-7.

81. Fountoulakis KN, Tsolaki M, Iacovides A, et al. The validation of the short form of the Geriatric Depression Scale (GDS) in Greece. Aging (Milano). 1999; 11(6): 367-72.

82. Greenberg SA. How to try this: the Geriatric Depression Scale: Short Form. Am J Nurs. 2007; 107(10): 60-9; quiz 9-70.

83. Lesher EL, Berryhill JS. Validation of the Geriatric Depression Scale-Short Form among inpatients. J Clin Psychol. 1994; 50(2): 256-60.

84. Pedraza 0, Dotson VM, Willis FB, et al. Internal Consistency and Test-Retest Stability of the Geriatric Depression Scale-Short Form in African American Older Adults. J Psychopathol Behav Assess. 2009; 31(4): 412-6

85. Sarkar S, Kattimani S, Roy G, et al. Validation of the Tamil version of short form Geriatric Depression Scale-15. J Neurosci Rural Pract. 2015; 6(3): 442-6.

86. Wong MT, Ho TP, Ho MY, et al. Development and inter-rater reliability of a standardized verbal instruction manual for the Chinese Geriatric Depression Scale-short form. Int J Geriatr Psychiatry. 2002; 17(5): 459-63.

87. Zalavadiya DD, Banerjee A, Sheth AM, et al. A Comparative Study of Depression and Associated Risk Factors among Elderly Inmates of Old Age Homes and Community of Rajkot: A Gujarati Version of the Geriatric Depression Scale-Short Form (GDS-G). Indian J Community Med. 2017; 42(4): 204-8.

88. Melzack R. The short-form McGill Pain Questionnaire. Pain. 1987; 30(2): 191-7.

89. Dudgeon D, Raubertas RF, Rosenthal SN. The short-form McGill Pain Questionnaire in chronic cancer pain. J Pain Symptom Manage. 1993; 8(4): 191-5.

90. Grafton KV, Foster NE, Wright CC. Test-retest reliability of the ShortForm McGill Pain Questionnaire: assessment of intraclass correlation coefficients and limits of agreement in patients with osteoarthritis. Clin J Pain. 2005; 21(1): 73-82.

91. Kitisomprayoonkul W, Klaphajone J, Kovindha A. Thai Short-form McGill Pain Questionnaire. J Med Assoc Thai. 2006; 89(6): 846-53.

92. Strand LI, Ljunggren AE, Bogen B, et al. The Short-Form McGill Pain Questionnaire as an outcome measure: test-retest reliability and responsiveness to change. Eur J Pain. 2008; 12(7): 917-25.

93. Wright KD, Asmundson GJ, McCreary DR. Factorial validity of the short-form McGill pain questionnaire (SF-MPQ). Eur J Pain. 2001; 5(3): 279-84.

94. Zinke JL, Lam CS, Harden RN, et al. Examining the cross-cultural validity of the english short-form McGill Pain Questionnaire using the matched moderated regression methodology. Clin J Pain. 2010; 26(2): 153-62.

95. Fowles JB, Fowler EJ, Craft C. Validation of claims diagnoses and selfreported conditions compared with medical records for selected chronic diseases. J Ambul Care Manage. 1998; 21(1): 24-34.

96. Heliovaara M, Aromaa A, Klaukka T, et al. Reliability and validity of interview data on chronic diseases. The Mini-Finland Health Survey. J Clin Epidemiol. 1993; 46(2): 181-91.

97. Martin LM, Leff M, Calonge N, et al. Validation of self-reported chronic conditions and health services in a managed care population. Am J Prev Med. 2000; 18(3): 215-8.

98. Coman EN, Wu HZ, Assari S. Exploring Causes of Depression and Anxiety Health Disparities (HD) by Examining Differences between 1:1 Matched Individuals. Brain Sci. 2018; 8(12).

99. Assari S. Self-rated Health and Mortality due to Kidney Diseases: Racial Differences in the United States. Adv Biomed Res. 2018; 7: 4.

100. DeSalvo KB, Bloser N, Reynolds K, et al. Mortality prediction with a single general self-rated health question. A meta-analysis. J Gen Intern Med. 2006; 21(3): 267-75. 
101. Franks P, Gold MR, Fiscella K. Sociodemographics, self-rated health, and mortality in the US. Soc Sci Med. 2003; 56(12): 2505-14.

102. Haga H, Shibata H, Ueno M, et al. [Relationship of self-rated health to mortality among the community elderly]. Nihon Koshu Eisei Zasshi. 1991; 38(10): 783-9.

103. Idler EL, Angel RJ. Self-rated health and mortality in the NHANES-I Epidemiologic Follow-up Study. Am J Public Health. 1990; 80(4): 446-52.

104. Mossey JM, Shapiro E. Self-rated health: a predictor of mortality among the elderly. Am J Public Health. 1982; 72(8): 800-8.

105. Schoenfeld DE, Malmrose LC, Blazer DG, et al. Self-rated health and mortality in the high-functioning elderly--a closer look at healthy individuals: MacArthur field study of successful aging. J Gerontol. 1994; 49(3): M109-15.

106. Barnes C, Cauvin E, Duran-Kim M, et al. A systematic review of the effectiveness of patient-centred care on emergency room visits, hospitalizations, unscheduled sick clinic visits, and missed school days for children with asthma. JBI Libr Syst Rev. 2011; 9(48 Suppl): 1-12.

107. Ejlertsson G, Berglund P, Henrysson I, et al. [Cooperative project. Fewer sick days when health services and insurance fund work together]. Vardfacket. 1992; 16(9): XVIII-XIX.

108. Linder LA, Bratton H, Nguyen A, et al. Comparison of good days and sick days of school-age children with cancer reflected through their drawings. Qual Life Res. 2017; 26(10): 2729-38.

109. Moore JC, Welniak EJ. Income measurement error in surveys: A review. Journal of official statistics. 2000; 16(4): 331

110. Turrell G. Income non-reporting: implications for health inequalities research. Journal of Epidemiology \& Community Health. 2000; 54(3): 207-14.

111. Kim S, Egerter S, Cubbin C, et al. Potential Implications of Missing Income Data in Population-Based Surveys: An Example from a Postpartum Survey in California. Public Health Reports. 2007; 122(6): 753-63

112. Carlsson AC, Starrin B, Gigante B, et al. Financial stress in late adulthood and diverse risks of incident cardiovascular disease and allcause mortality in women and men. BMC Public Health. 2014; 14: 17.

113. Goncalves A. [Financial stress: A prognostic factor for cancer survival!]. Bull Cancer. 2016; 103(4): 318.

114. Shah SJ, Krumholz HM, Reid KJ, et al. Financial stress and outcomes after acute myocardial infarction. PLoS One. 2012; 7(10): e47420.

115. Rodriguez JM. Health disparities, politics, and the maintenance of the status quo: A new theory of inequality. Soc Sci Med. 2018; 200: 36-43.

116. Eisenberg D, Gollust SE, Golberstein E, et al. Prevalence and correlates of depression, anxiety, and suicidality among university students. Am J Orthopsychiatry. 2007; 77(4): 534-42.

117. Daly M, Boyce C, Wood A. A social rank explanation of how money influences health. Health Psychol. 2015; 34(3): 222-30.

118. Dassah E, Aldersey HM, McColl MA, et al. 'When I don't have money to buy the drugs, I just manage.'-Exploring the lived experience of persons with physical disabilities in accessing primary health care services in rural Ghana. Soc Sci Med. 2018; 214: 83-90.

119. Gee S, Vargas J, Foster AM. "We need good nutrition but we have no money to buy food": sociocultural context, care experiences, and newborn health in two UNHCR-supported camps in South Sudan BMC Int Health Hum Rights. 2018; 18(1): 40.

120. Margolis R, Myrskyla M. Family, money, and health: regiona differences in the determinants of life satisfaction over the life course. Adv Life Course Res. 2013; 18(2): 115-26.
121. Mirvis DM, Klesges LM. Poverty and health: a simple matter of money? Tenn Med. 1999; 92(7): 258-60.

122. Plagerson S, Patel V, Harpham T, et al. Does money matter for mental health? Evidence from the Child Support Grants in Johannesburg, South Africa. Glob Public Health. 2011; 6(7): 760-76.

123. Sinclair RR, Cheung JH. Money Matters: Recommendations for Financial Stress Research in Occupational Health Psychology. Stress Health. 2016; 32(3): 181-93.

124. Tezoquipa IH, Monreal LA, Trevino-Siller S. "Without money you're nothing": poverty and health in Mexico from women's perspective. Rev Lat Am Enfermagem. 2005; 13(5): 626-33.

125. Warr DJ, Tacticos T, Kelaher M, et al. 'Money, stress, jobs': residents' perceptions of health-impairing factors in 'poor' neighbourhoods. Health Place. 2007; 13(3): 743-56.

126. Siahpush M, Spittal M, Singh GK. Smoking cessation and financial stress. J Public Health (Oxf). 2007; 29(4): 338-42.

127. Financial stress linked to periodontal disease. J Am Dent Assoc. 1995; 126(10): 1346.

128. Datta BK, Husain MJ, Husain MM, et al. Noncommunicable diseaseattributable medical expenditures, household financial stress and impoverishment in Bangladesh. SSM Popul Health. 2018; 6: 252-8.

129. Adams DR, Meyers SA, Beidas RS. The relationship between financial strain, perceived stress, psychological symptoms, and academic and social integration in undergraduate students. J Am Coll Health. 2016; 64(5): 362-70.

130. Assari S. Unequal Gain of Equal Resources across Racial Groups. Int J Health Policy Manag. 2017; 7(1): 1-9.

131. Assari S. Health Disparities due to Diminished Return among Black Americans: Public Policy Solutions. Social Issues and Policy Review. 2018; 12(1): 112-45.

132. Jefferson AL, Gibbons LE, Rentz DM, et al. A life course model of cognitive activities, socioeconomic status, education, reading ability, and cognition. J Am Geriatr Soc. 2011; 59(8): 1403-11.

133. Sisco S, Gross AL, Shih RA, et al. The role of early-life educational quality and literacy in explaining racial disparities in cognition in late life. J Gerontol B Psychol Sci Soc Sci. 2015; 70(4): 557-67.

134. Manly JJ, Jacobs DM, Touradji P, et al. Reading level attenuates differences in neuropsychological test performance between African American and White elders. J Int Neuropsychol Soc. 2002; 8(3): 3418.

135. Scarmeas N, Albert SM, Manly JJ, et al. Education and rates of cognitive decline in incident Alzheimer's disease. J Neurol Neurosurg Psychiatry. 2006; 77(3): 308-16.

136. Manly JJ, Touradji P, Tang MX, et al. Literacy and memory decline among ethnically diverse elders. I Clin Exp Neuropsychol. 2003; 25(5): 680-90.

137. Zahodne LB, Glymour MM, Sparks C, et al. Education does not slow cognitive decline with aging: 12-year evidence from the victoria longitudinal study. J Int Neuropsychol Soc. 2011; 17(6): 1039-46.

138. Lee DB, Peckins MK, Heinze JE, et al. Psychological pathways from racial discrimination to cortisol in African American males and females. J Behav Med. 2018; 41(2): 208-20.

139. Hudson DL, Neighbors HW, Geronimus AT, et al. The relationship between socioeconomic position and depression among a US nationally representative sample of African Americans. Soc Psychiatry Psychiatr Epidemiol. 2012; 47(3): 373-81.

140. Agrigoroaei S, Lee-Attardo A, Lachman ME. Stress and Subjective Age: Those With Greater Financial Stress Look Older. Res Aging. 2017; 39(10): 1075-99. 
141. Freshman A. Financial disaster as a risk factor for posttraumatic stress disorder: internet survey of trauma in victims of the Madoff Ponzi scheme. Health Soc Work. 2012; 37(1): 39-48.

142. Gonzalez G, Vives A. Work Status, Financial Stress, Family Problems, and Gender Differences in the Prevalence of Depression in Chile. Ann Work Expo Health. 2019.

143. Robinson OJ, Bond RL, Roiser JP. The impact of stress on financial decision-making varies as a function of depression and anxiety symptoms. PeerJ. 2015; 3: e770.

144. Assari S. Whites but Not Blacks Gain Life Expectancy from Social Contacts. Behav Sci (Basel). 2017; 7(4)

145. Navarro V. Race or class, or race and class. Int J Health Serv. 1989; 19(2): 311-4.

146. Navarro V. Race or class versus race and class: mortality differentials in the United States. Lancet. 1990; 336(8725): 1238-40.

147. Navarro V. Race or class or race and class: growing mortality differentials in the United States. Int J Health Serv. 1991; 21(2): 22935.

148. Jackson AP, Brooks-Gunn J, Huang C, et al. Single mothers in lowwage jobs: Financial strain, parenting, and preschoolers' outcomes. Child development. 2000; 71(5): 1409-23.

149. Jackson AP. The role of social support in parenting for low-income, single, black mothers. Social Service Review. 1998; 72(3): 365-78.

150. Hamilton D, Darity Jr W, Price AE, et al. Umbrellas don't make it rain Why studying and working hard isn't enough for Black Americans. New York: The New School. 2015.

151. Hamilton D, Darity Jr W. Race, Wealth, and Intergenerational Poverty: There will never be a post-racial America if the wealth gap persists. The American Prospect. 2009; 20(7): A10-A2.

152. Hamilton D, Darity Jr W. Can 'baby bonds' eliminate the racial wealth gap in putative post-racial America? The Review of Black Political Economy. 2010; 37(3-4): 207-16.

153. Lincoln KD, Taylor RJ, Bullard KM, et al. Emotional support, negative interaction and DSM IV lifetime disorders among older African Americans: findings from the National Survey of American Life (NSAL). Int J Geriatr Psychiatry. 2010; 25(6): 612-21.

154. Lincoln KD, Taylor RJ, Watkins DC, et al. Correlates of Psychological Distress and Major Depressive Disorder Among African American Men. Res Soc Work Pract. 2011; 21(3): 278-88.

155. Lincoln KD, Taylor RJ, Chatters LM. Correlates of emotional support and negative interaction among older Black Americans. J Gerontol B Psychol Sci Soc Sci. 2003; 58(4): S225-33.

156. Oliver M, Shapiro T. Black wealth/white wealth: A new perspective on racial inequality: Routledge 2013.

157. Oliver ML, Shapiro TM. Black wealth/white wealth: New York: Routledge 1999.

158. Clancy MM, Beverly SG, Sherraden M, et al. Testing universal child development accounts: Financial effects in a large social experiment. Social Service Review. 2016; 90(4): 683-708.

159. Morrow-Howell N, Sherraden M. Financial capability and asset holding in later life: A life course perspective: Oxford University Press 2014

160. Sherraden M. Can the poor save?: Saving and asset building in individual development accounts: Routledge 2017.

161. Sherraden M, Sherraden MS, Moore AM, et al. Saving in low-income households: Evidence from interviews with participants in the American Dream Demonstration: Center for Social Development, George Warren Brown School of Social Work. 2005.
162. Huang J, Beverly SG, Kim Y, et al. Exploring a model for integrating Child Development Accounts Exploring a model for integrating Child Development Accounts with social services for vulnerable families. with social services for vulnerable families. Journal of Consumer Affairs. 2019; 53(3): 770-95.

163. Huang J, Beverly SG, Kim Y, et al. Exploring a Model for Integrating Child Development Accounts with Social Services for Vulnerable Families. Journal of Consumer Affairs. 2019; 53(3): 770-95.

164. Aguila E, Kapteyn A, Smith JP. Effects of income supplementation on health of the poor elderly: the case of Mexico. Proc Natl Acad Sci U S A. $2015 ; 112(1): 70-5$

165. Assari S, Bazargan M. Protective Effects of Educational Attainment Against Cigarette Smoking; Diminished Returns of American Indians and Alaska Natives in the National Health Interview Survey. International Journal of Travel Medicine and Global Health. 2019.

166. Assari S. Education Attainment and ObesityDifferential Returns Based on Sexual Orientation. Behav Sci (Basel). 2019; 9(2).

167. Avendano M, Glymour MM. Stroke disparities in older Americans: is wealth a more powerful indicator of risk than income and education? Stroke. 2008; 39(5): 1533-40.

168. Kennedy G, Nantel G, Brouwer ID, et al. Does living in an urban environment confer advantages for childhood nutritional status? Analysis of disparities in nutritional status by wealth and residence in Angola, Central African Republic and Senegal. Public Health Nutr. 2006; 9(2): 187-93.

169. Kohler TA, Smith ME, Bogaard A, et al. Greater post-Neolithic wealth disparities in Eurasia than in North America and Mesoamerica. Nature. 2017; 551(7682): 619-22.

170. Lersch PM. The Marriage Wealth Premium Revisited: Gender Disparities and Within-Individual Changes in Personal Wealth in Germany. Demography. 2017; 54(3): 961-83.

171. Makaroun LK, Brown RT, Diaz-Ramirez LG, et al. Wealth-Associated Disparities in Death and Disability in the United States and England. JAMA Intern Med. 2017; 177(12): 1745-53.

172. McKernan SM, Ratcliffe C, Simms M, et al. Do racial disparities in private transfers help explain the racial wealth gap? New evidence from longitudinal data. Demography. 2014; 51(3): 949-74.

173. Pfeffer FT, Danziger S, Schoeni RF. Wealth Disparities before and after the Great Recession. Ann Am Acad Pol Soc Sci. 2013; 650(1): 98-123.

174. Pollack CE, Cubbin C, Sania A, et al. Do wealth disparities contribute to health disparities within racial/ethnic groups? J Epidemiol Community Health. 2013; 67(5): 439-45.

175. Reynolds SA, Andersen C, Behrman J, et al. Disparities in children's vocabulary and height in relation to household wealth and parental schooling: A longitudinal study in four low- and middle-income countries. SSM Popul Health. 2017; 3: 767-86.

176. Rossouw L, Bago d'Uva T, van Doorslaer E. Poor Health Reporting? Using Anchoring Vignettes to Uncover Health Disparities by Wealth and Race. Demography. 2018; 55(5): 1935-56.

177. Eiser AR, Ellis G. Viewpoint: Cultural competence and the African American experience with health care: The case for specific content in cross-cultural education. Acad Med. 2007; 82(2): 176-83.

178. Gullickson A. Racial boundary formation at the dawn of Jim Crow: the determinants and effects of black/mulatto occupational differences in the United States, 1880. AJS. 2010; 116(1): 187-231.

179. Hua CL, Bardo AR, Brown JS. Mistrust in Physicians does not Explain Black-white Disparities in Primary Care and Emergency Department Utilization: The Importance of Socialization During the Jim Crow era. J Natl Med Assoc. 2018; 110(6): 540-6. 
180. Krieger N, Chen JT, Coull BA, et al. Jim Crow and premature mortality among the US Black and White population, 1960-2009: an ageperiod-cohort analysis. Epidemiology. 2014; 25(4): 494-504.

181. Krieger N, Waterman PD, Kosheleva A, et al. Racial discrimination \& cardiovascular disease risk: my body my story study of 1005 US-born black and white community health center participants (US). PLoS One. 2013; 8(10): e77174.

182. Norwood CR. Mapping the Intersections of Violence on Black Women's Sexual Health within the Jim Crow Geographies of Cincinnati Neighborhoods. Frontiers (Boulder). 2018; 39(2): 97-135.

183. Smith DB. Racial and ethnic health disparities and the unfinished civil rights agenda. Health Aff (Millwood). 2005; 24(2): 317-24.

184. Cermakova P, Pikhart H, Kubinova R, et al. Education as inefficient resource against depressive symptoms in the Czech Republic: crosssectional analysis of the HAPIEE study. European Journal of Public Health. 2020

185. Baker RS, Bazargan M, Bazargan-Hejazi S, et al. Access to vision care in an urban low-income multiethnic population. Ophthalmic Epidemiol. 2005; 12(1): 1-12.

186. Baker RS, Watkins NL, Wilson MR, et al. Demographic and clinical characteristics of patients with diabetes presenting to an urban public hospital ophthalmology clinic. Ophthalmology. 1998; 105(8): 1373-9.

187. Bazargan M, Calderon JL, Heslin KC, et al. A profile of chronic mental and physical conditions among African-American and Latino children in urban public housing. Ethn Dis. 2005; 15(4 Suppl 5): S5-3-9.

188. Bazargan M, Hamm-Baugh VP. The relationship between chronic illness and depression in a community of urban black elderly persons. J Gerontol B Psychol Sci Soc Sci. 1995; 50(2): S119-27.

189. Bazargan M, Norris K, Bazargan-Hejazi S, et al. Alternative healthcare use in the under-served population. Ethn Dis. 2005; 15(4): 531-9.

190. Tataw D, Bazargan-Hejazi S, James FW. Actualizing a provider alliance to expand health services access to a low-income urban community. Soc Work Public Health. 2011; 26(7): 651-71.

191. Tataw DB, Bazargan-Hejazi S, James FW. Health services utilization, satisfaction, and attachment to a regular source of care among participants in an urban health provider alliance. J Health Hum Serv Adm. 2011; 34(1): 109-41.

192. Rodriguez JM, Geronimus AT, Bound J, et al. Black lives matter: Differential mortality and the racial composition of the U.S. electorate, 1970-2004. Soc Sci Med. 2015; 136-137: 193-9.

193. Purtle J. Lives matter. Do votes? Invited commentary on "Black lives matter: Differential mortality and the racial composition of the U.S. electorate, 1970-2004". Soc Sci Med. 2015; 136-137: 190-2.

194. Cermakova P, Pikhart H, Ruiz M, et al. Socioeconomic position in childhood and depressive symptoms in later adulthood in the Czech Republic. Journal of Affective Disorders. 2020. 